\title{
Resenha
}

\section{Um olhar sobre as experiências de políticas públicas de juventude na América Latina*}

\author{
Dávila, Oscar (org.). Políticas públicas \\ de juventud en America Latina: \\ políticas nacionales. Viña del Mar: \\ Ediciones CIDPA, 2003, 303p. \\ Dávila, Oscar (org.). Políticas públicas \\ de juventud en America Latina: \\ políticas locales. Viña del Mar: \\ Ediciones CIDPA, 2003, 162p.
}

Os dois volumes sobre políticas públicas de juventude, organizados e publicados pelo Centro de Investigación y Difusión Poblacional de Achupallas, Viña del Mar (CIDPA), constituem material extremamente rico e bastante completo, que reúne textos sobre as experiências locais e nacionais de políticas públicas de juventude de dez países da América Latina. Contêm textos diversificados, elaborados não somente por acadêmicos como por membros de organizações de assessoria técnica (nacionais ou internacionais) ou, no caso de algumas experiências locais de políticas pú-

* Texto apresentado como comentário aos dois livros acima referidos, durante o seminário regional Juventud, Diversidad Cultural e Desarrollo Local, organizado no âmbito da Conferencia Regional de Macrocidades e realizado em Montevidéu, de 17 a 19 de setembro de 2003. blicas, pelos próprios gestores públicos responsáveis por essas políticas. Essa diversidade de olhares é, sem dúvida, uma grande riqueza.

Em primeiro lugar, quero assinalar a importância do trabalho realizado por CIDPA, uma organização não-governamental chilena bastante sui generis no panorama atual das organizações nãogovernamentais, pois realiza exclusivamente atividades de pesquisa, avaliação e publicação, oportunizando a difusão de um acervo extremamente qualificado de reflexões e pesquisas sobre temáticas ligadas à juventude na América Latina. CIDPA adota também uma política de democratização do conhecimento muito interessante, disponibilizando todos os textos publicados no portal da instituição: www.cidpa.cl.

Em segundo lugar, quero explicitar o lugar a partir do qual observo e reflito sobre a realidade latino-americana. Vivo e trabalho no Brasil há 13 anos; nesse tempo, entretanto, passei mais de um ano trabalhando no Chile, na UNICEF, onde conheci de perto o trabalho das instituições públicas nacionais e locais que atuam no campo da juventude. Passei também dois anos trabalhando na Itália, meu país de origem, em ações de políticas públicas para a juventude, implementadas em parceria entre o governo e as organizações da sociedade civil.

O primeiro comentário sobre os dois livros diz respeito a um sentimento geral: em matéria de políticas públicas de juventude, o panorama é ainda bastante desalentador; apesar de existirem em quase todos os países instituições públicas dedicadas a formular e implementar políticas de juventude, ${ }^{1}$ as inúmeras mudanças de rumos, de planos propostos e de programas implementados, e até de nomenclatura das instituições responsáveis, sugerem que essas políticas ainda sofrem de significativa falta de legitimidade e de extrema precariedade institucional, programática e financeira.

Particularmente, no que diz respeito aos gestores dessas políticas, parece que, via de regra, padecem de uma série de limitações: baixa legitimidade no interior do aparato institucional governamental; em conseqüência, não conseguem assumir a tarefa institucional de coordenar os diferentes programas e iniciativas públicas dirigidas aos jovens e se limitam a executar algum programa específico e de alcance limitado; falta de dotação orçamentária significativa; falta de capacitação; atrelamento a interesses políticos partidários, por causa de sua

${ }^{1}$ Com exceção do Brasil, na América Latina as instituições e as iniciativas de políticas públicas de juventude começaram a ser impulsionadas a partir da celebração do Ano Internacional da Juventude, promovido pelas Nações Unidas, em 1985. 
origem política de que, geralmente, a juventude é partidária.

O fato de serem, também geralmente, eles mesmos jovens, se por um lado pode significar maior disponibilidade e sensibilidade em relação às questões que afetam o universo juvenil, por outro lado torna bastante difícil sua inserção dentro do aparato burocrático governamental, no qual são identificados como "meninos" que podem ser chamados na hora de organizar alguma festa ou evento público para dar visibilidade ao governo. Por sua vez, o fato de ter militado em alguma organização juvenil (estudantil ou partidária) permite a esses jovens fazerem-se porta-vozes das reivindicações expressas por aquelas organizações, $o$ que não significa forçosamente ter a sensibilidade para considerar e se relacionar com a grande diversidade do universo juvenil, organizado ou não.

O dilema entre ser jovem no meio do aparato governamental e, ao mesmo tempo, ser um braço do governo no meio dos jovens torna difícil para os gestores definirem sua própria identidade e seu próprio papel, no meio de inúmeros pedidos, reivindicações, anseios, necessidades às vezes contrastantes. Como manter e ampliar a relação com a juventude organizada e, ao mesmo tempo, conquistar legitimidade dentro do aparato governamental?

Por outro lado, pensando nos eixos dessas políticas, em grandes objetivos, podemos formular três cenários:

1. O mais clássico, a repressão e o controle social: o jovem é considerado um problema, particularmente no que diz respeito à segurança nacional; além da repressão, considera-se importante realizar ações preventivas, para evitar as situações de risco e de violência nas quais se inserem os jovens, como causadores ou vítimas.

2. A mobilização social dos jovens, em busca do consenso político: para a definição desse objetivo converge a própria formação política dos gestores, geralmente construída no seio da juventude partidária. Trabalhar com jovens significa mobilizá-los em alguma eleição ou campanha política, para que colaborem com suas energias na construção do consenso.

3. A integração social: o jovem como agente principal de desenvolvimento, enfatizando a vontade natural do jovem de fazer, de se ocupar em alguma ação prática para a melhoria das condições de vida de seu entorno. Nesse terceiro eixo se inscrevem especificamente muito dos trabalhos desenvolvidos pelas organizações não-governamentais. ${ }^{2}$ Essa ótica tem um respaldo financeiro e teórico importante, no que diz respeito, por exemplo, à ação do Banco Interamericano de Desenvolvimento (BID) e às elaborações de figuras de prestígio, como Ernesto Rodriguez, um dos históricos na discussão sobre políticas de juventude na América Latina, que tem também um ensaio publicado no livro das políticas nacionais do CIDPA $^{3}$. As ações implementadas podem ser enquadradas dentro da proposta neoliberal do Estado mínimo, pela qual a população é chamada a resolver os problemas que lhe dizem respeito, beneficiando-se de escassos recursos públicos.

É interessante notar que é mais fá-

${ }^{2}$ Nessa discussão refiro-me especificamente às organizações não-governamentais que estruturam sua ação ao redor da implementação de projetos e serviços sociais, financiados principalmente por organismos públicos e privados nacionais, as quais Regina Novaes definiria como de terceira ou quarta geração.

${ }^{3}$ Ernesto Rodriguez, "Juventud, crisis y políticas públicas en el Uruguay: un esquemático balance de los anos noventa y propuestas para esta primera década del nuevo siglo" (cf. Políticas nacionales, p. 47-88). cil chegar a implementar ações de apoio à capacidade de organização e ação autônoma dos jovens (que considero, como explicitarei a seguir, o objetivo mais interessante na ação com jovens) partindo do primeiro do que do terceiro cenário. $\mathrm{O}$ texto que relata as experiências mexicanas de políticas locais ${ }^{4}$ exemplifica bem o trabalho desenvolvido nesses dois eixos. Por um lado, é apresentada a experiência de um governo local que parte da consideração do jovem como problema, jovem violento para o qual é preciso fazer alguma coisa, no intuito da prevenção e do controle social, e que passa, paulatinamente, a se relacionar com as "galeras" e "bandas" organizadas, começando a desenvolver ações no intuito de envolver os próprios jovens como agentes de intervenção, de mediação de conflitos e busca de alternativas por meio das "bandas", chegando finalmente a formular um programa de apoio às organizações juvenis. Por outro lado, é analisada a experiência de uma organização não-governamental que visa à formação de um grupo de jovens, impulsionando-os a elaborar e implementar projetos para a melhoria do bem-estar da comunidade. O grupo é fortalecido, mas fica bastante dependente da ação da organização não-governamental; a autonomia de seus membros com relação a essa organização é muito relativa ${ }^{5}$. Nessas experiências, geralmente, se desconsidera e se anula o conflito generacional: jovens e adultos pare-

${ }^{4}$ Moisés Dominguez e Héctor Morales, "Políticas locales de juventud en México" (cf. Políticas locales, p.13-52).

${ }^{5}$ É interessante notar que, no meio das organizações não-governamentais que desenvolvem trabalhos com essa perspectiva, umas das questões críticas postas é a discussão sobre qual seria o momento certo para cortar o cordão umbilical com o grupo de jovens (na maioria das vezes, esse momento parece não chegar nunca). 
cem trabalhar juntos na maior harmonia e com os mesmos objetivos.

Coloca-se aqui a visão que Helena Abramo formula muito bem, quando fala dos jovens considerados como meio e não como fim das ações. ${ }^{6}$ Por exemplo, existem no Recife grupos de música que fazem shows para arrecadar alimentos para as crianças carentes. $\mathrm{O}$ paradoxo é que muitas vezes esses jovens são beneficiários de algum programa governamental ou não-governamental que oferece bolsas, mas ninguém imagina que eles possam fazer shows para arrecadar recursos para eles mesmos, ou seja, ser sujeitos de sua própria sustentação. Raramente os jovens são incentivados a implementar projetos de intervenção social que tenham como objetivo melhorar sua própria vida, enquanto jovens, e não a vida de outros. O protagonismo é no sentido de uma ação que se dirige a outros, uma ação que muitas vezes é definida por e para outros.

É interessante notar que essa difusão do conceito de protagonismo juvenil existe exclusivamente no Brasil. ${ }^{7}$

${ }^{6}$ Quando me refiro às falas de Helena Abramo, autora de numerosos textos sobre a temática da juventude no Brasil (cf. particularmente: Cenas juvenis: punks e darks no espetáculo urbano, Editora Scritta: São Paulo, 1994) faço referência a palestras e debates realizados por ela, particularmente como consultora do Projeto Redes e Juventudes.

${ }^{7}$ Os autores do texto sobre as políticas públicas brasileiras - Juventud y políticas públicas em Brasil (cf. Políticas nacionales, p. 265-303), Paulo Carrano e Marília Sposito elaboraram um texto muito importante, sistematizando as ações desenvolvidas pelos governos federais anteriores e desenvolvendo uma análise crítica e útil para definir as ações no novo Governo Lula; devem-nos, entretanto, uma análise sobre o uso (e abuso) do conceito de protagonismo juvenil no Brasil.
Quando usado em outros países da América Latina, os significados são bem distintos. Outra questão que não se observa na América Latina, ao contrário do que se vê no Brasil, é relativa à definição de faixa etária. De fato, nos textos brasileiros relatam-se e confundem-se projetos dirigidos a crianças, adolescentes e jovens.

A meu ver, vários textos abordam questões mais interessantes que as relativas ao tipo de institucionalidade, mais apropriada para definir e implementar políticas públicas de, com e para jovens, e com que tipo de formato. Por exemplo, os da Colômbia ${ }^{8}$ e do Chile $^{9}$ sobre políticas locais ampliam essa discussão de forma bastante aprofundada, mas quase exclusivamente técnica.

Miguel Abad, autor de um dos textos mais completos e interessantes da coletânea, ${ }^{10}$ assinala que se as políticas públicas são formuladas respondendo a demandas, a necessidades, é interessante perguntar: Quem formula essas demandas? Quem se mobiliza para defender uma efetiva realização dessas políticas? Quais setores da sociedade podem mobilizar-se a favor da juventude? ${ }^{11}$

${ }^{8}$ Luz Marina Cruz Henao, "La política pública de juventud en Medellín, Colômbia: un sueño en construcción" (cf. Políticas locales, p. 131-140).

${ }^{9}$ Juan Cláudio Silva, "Políticas locales de juventud en Chile: intentando develar el sujeto" (cf. Políticas locales, p. 101-130).

${ }^{10}$ Miguel Abad, "Las políticas de juventud desde la perspectiva de la relación entre convivencia, ciudadania y nueva condición juvenil en Colombia" (cf. Políticas nacionales, p. 229-264).

${ }^{11}$ É importante nesse sentido resgatar a história da mobilização realizada no Brasil em favor dos direitos da criança e do adolescente, quando se conseguiu aglutinar diferentes atores ao redor da bandeira dos direitos e da promulgação do Estatuto da Criança e do Adolescente.
Pensando na debilidade dos atores indicada anteriormente e considerando os jovens como sujeitos, penso que os atores fundamentais para essa mobilização e formulação de demandas são os próprios jovens. Nesse sentido, é preciso indagar: Como podemos apoiar, fortalecer essa expressão das demandas juvenis? Como bem coloca Helena Abramo: Como podemos apoiar a tradução dessas demandas, formuladas geralmente de forma não sistemática e através de diferentes linguagens, em questões a serem colocadas no espaço público? Como podemos fortalecer os jovens para que se tornem atores políti$\cos$ ? Seria interessante indagar os efeitos, os acúmulos, as aprendizagens realizadas por aquelas experiências que tem como objetivo o apoio à organização dos jovens, à construção de seus espaços de autonomia e de experimentação da cidadania, de participação na definição das políticas públicas.

A proposta mais significativa, entre as relatadas nos livros em análise, que se enquadra nessa perspectiva é a do Projeto Jovenes por Jovenes, elaborado na Argentina no curto governo De la Rúa e que, infelizmente, em virtude da sua caída, não chegou a ser implementada em nível nacional (se bem que em nível local existem muitas experiências que seguem as mesmas proposições). Essa proposta parece ser uma concretização das concepções elaboradas por Miguel Abad em seu texto. Depois de ter traçado um quadro histórico que sintetiza as principais orientações das políticas de juventude na América Latina, ele faz uma comparação muito interessante entre políticas de integração para e pelos jovens e políticas afirmativas, com e a partir dos jovens, colocando muito claramente como central a questão da necessidade de fortalecer e legitimar os jovens como atores políticos, com capacidade e possibilidade de colocar suas demandas no espaço público; e também de sensibili- 
zar a opinião pública para que escute e considere essas demandas. Precisamos, nesse sentido, atuar ao lado dos jovens, fortalecendo sua capacidade de intervenção e organização, e, ao mesmo tempo, ao lado da sociedade em geral, para criar um entorno favorável a essa interlocução com os jovens.

Retomando nossa análise, o Projeto Jovenes por Jovenes, descrito por Evaristo Carriego, ${ }^{12}$ tinha quatro linhas de ação: fortalecimento das organizações juvenis; apoio à realização de projetos sociais por parte dos jovens; abertura de casas da juventude; estímulo à criação de "mesas de negociação"13 entre as organizações juvenis e com outros atores sociais. Essas quatro linhas concretizam a perspectiva de "políticas de promoção integral que consideram os jovens como seus sujeitos de direitos" (Carriego, Políticas locales, p. 88), que Abad denomina de políticas afirmativas.

A criação de "mesas de negociação" é uma prática que está sendo também muito significativa no Peru, onde os jovens assumiram um papel central na luta pela derrota de Fujimori. O texto de Luis Montoya, ${ }^{14}$ relatando o caso do Peru, é muito interessante mesmo porque talvez seja o único que aprofunda a questão de como as políticas de juventude estão inseridas no marco vigente de políticas sociais, ou seja, as políticas neoliberais compensatórias, implementadas para "tapar buracos" provocados pelas políticas econômicas neoliberais, predatórias e excludentes.

${ }^{12}$ Evaristo Carriego, "Programa jovenes por jovenes: de las visiones y las colas de la historia en los programas de juventud" (cf. Politicas locales, p. 85-100).

${ }^{13}$ Em espanhol: concertación.

${ }^{14}$ Luis W. Montoya, "De las marchas de las juventudes políticas al camino de las políticas de juventud en Perú" (cf. Politicas nacionales, p. 167-204).
Montoya mostra também como por parte do mundo adulto são criadas representações sobre os jovens, das quais estes mesmos se apropriam. Pelo fato de os jovens terem sido apontados, pela opinião pública e pela imprensa, como uma força política importante na oposição ao governo Fujimori, todos os quatro candidatos presidenciais colocaram, em seu programa de governo, o objetivo de criar organismos responsáveis pelas políticas públicas de juventude. Os jovens se apropriaram dessa representação e de fato começaram a se organizar, a criar fóruns, "mesas de negociação", espaços de discussão e de interlocução dos jovens com outros atores sociais, na perspectiva de participar na elaboração de políticas públicas de juventude.

É urgente e necessário - e fiz esse pedido ao CIDPA - organizar um terceiro tomo para contar a história e avaliar o impacto dessas experiências de organização e de participação dos jovens na definição das políticas públicas, desses fóruns e "mesas de negociação", de encontro e diálogo entre diferentes. Tanto na Argentina, como no Peru, na Colômbia e no México já existem significativas experiências acumuladas nesse sentido, que é preciso analisar, avaliar, discutir, sobretudo agora que, no Brasil, estão começando a ser criados esses organismos, como os conselhos de juventudes, os fóruns municipais etc. É necessário e urgente avaliar de que forma se fortalece a capacidade de atuação autônoma das organizações juvenis, autônoma também em relação às organizações não-governamentais; a possibilidade de os jovens se organizarem em múltiplas e diferentes formas; dialogar entre diferentes; como essas organizações terem papel ativo na definição das políticas. De que forma isso está acontecendo? Com que resultados? Quais os saldos positivos, quais os negativos, quais aprendizagens podemos acumular des- sas experiências? Como se constrói o diálogo com os distintos atores sociais, com os setores público e privado, as organizações não-governamentais? Quais espaços institucionais são os mais bem-sucedidos nesse sentido? Considero esse campo extremamente interessante a ser questionado e sistematizado, analisando a história das políticas de juventude na América Latina, a partir da perspectiva das organizações juvenis.

Outra questão posta por Luis Montoya é sobre o modelo de integração social que se quer impor, tentando diluir e fazer desaparecer todo e qualquer conflito social. Ele coloca, ao invés, que os jovens estão inseridos dentro de relações de poder; portanto, é dentro dessas relações de poder e dos conflitos que delas se geram que é possível conquistar efetivamente um espaço de poder na sociedade, mobilizar os jovens e fortalecer sua capacidade de atuação.

Finalmente, gostaria de concluir com uma observação sobre esse discurso instalado, essa dicotomia entre considerar o jovem como problema ou como solução. Fico pensando na minha juventude, colocando-me do ponto de vista enquanto jovem, e me parece que deve ser muito mais pesado ser indicado como solução do que como problema, pois essa história de ser solução coloca nos ombros dos jovens um peso, uma responsabilidade muito grande. Isso está relacionado com outra questão, à qual não se faz referência nos textos dos livros sobre políticas públicas: todas as dificuldades do ser jovem, de viver essa fase de transição, de construção de um projeto de vida, de individualização, provocam uma angústia terrível.

Outro dia discutia com um grupo de pessoas ligadas a organizações nãogovernamentais, no Recife, a respeito do que é ser jovem. Propus que cada um colocasse num papel uma palavra, uma expressão sobre o que é ser jovem. 
Todas as colocações diziam respeito a: energia, possibilidade, abertura para o mundo, inquietação positiva, vontade de transformação; todos diziam que ser jovem é fantástico, porque todas as possibilidades estão ainda abertas. Mas muitos jovens que conheço manifestam uma grande angústia, porque justamente as portas não estão abertas, o mercado de trabalho está fechado, as possibilidades de construir a própria identidade experimentando os limites das próprias capacidades e formas de atuação são extremamente limitadas, sobretudo pelos jovens das camadas populares. O mundo, de maneira geral, nunca foi tão fechado como nesse momento para a transformação social. Aquilo que alguns autores definem como "tempo liberado" da juventude, é liberado para quê? Como me coloco nesse mundo, de que forma, com base em quais experiências posso estruturar minha identidade, nesse vazio de diálogo com os adultos, os pais, os professores? Tudo isso provoca uma grande angústia. E acho que em nenhum dos programas descritos nesses livros percebe-se existir alguma forma de acompanhar (que não é dirigir) os jovens em seus percursos, em suas buscas; uma forma de estar presente, acompanhando também as experimentações, a necessidade de provar seus limites (que está relacionado com a vivência corporal, o uso das drogas, por exemplo), de correr riscos etc. ${ }^{15}$

Livia De Tommasi Doutora em Sociologia pela Sorbonne - Paris I Coordenadora do Projeto Redes e Juventudes, com sede no Recife,PE E-mail:1illi@uol.com.br

${ }^{15}$ Sobre essa questão do risco, um texto muito instigante é o de Salvatore La Mendola, "O sentido do risco", em La generazione invisibile: inchiesta sui giovani del nostro tempo, Milano: Il sole 24 ore, 1999. 